\title{
LA PRENSA CATOLICA DURANTE EL FRANQUISMO: EL CASO DE CRITERIO. REVISTA DE PROBLEMAS CONTEMPORANEOS. (1947-1950)
}

José A. Gilabert Ortega

Universidad de Alicante

\section{INTRODUCCION}

"Es justo decir que fue probablemente el intento más cercano al éxito por proporcionar un barniz cultural al catolicismo político de la época"1. Estas palabras de Javier Tusell sirven a nuestro propósito por abordar, desde las páginas que siguen, una primera aproximación al análisis formal y temático de una singular publicación, que nacida al amparo de un sector importante de la Asociación Católica Nacional de Propagandistas, vino a llenar un importante hueco en el débil sector editorial de la España de posguerra: la revista Criterio (1947-1950).

La aparición de la revista hay que ponerla en relación con el relanzamiento de las actividades desplegadas por la ACNP, a partir de 1945, tras una etapa de lenta recuperación de su afiliación, cuadros dirigentes y patrimonio, seriamente afectados al finalizar la guerra civil ${ }^{2}$. Un relanzamiento que tendrá su principal punto de apoyo merced a la incorporación de Alberto Martín Artajo, presidente de la Acción Católica Española y prohombre de la ACNP, al importante ministerio de Asuntos Exteriores; así como la de otros señalados propagandistas a importantes cargos de responsabilidad. Como señala Guy Hermet: "Al llamarle el Caudillo fuerza a la Iglesia a dar su aval a la tentativa de reorientación del Estado Nacional o, en caso contrario, al negarse a ello de modo explícito, con todos los riesgos que un tal rechazo entrañaría para la estabilidad del país"3.

La incorporación de Alberto Martín Artajo a las tareas gubernamentales no estuvo exenta de problemas. Algunas semanas antes parecía todavía el menos "ministrable" de los candidatos que la Acción Católica podía aportar al Gobierno. Él mismo era consciente de las escasas posibilidades con que contaba, frente a las ventajas de algunos de sus compañeros, para acceder a una cartera ministerial debido a la neutralidad política que se requería normalmente para el desempeño de la más alta instancia de Acción Católica Española.

En esta dirección hemos de entender el apoyo que Martín Artajo obtuvo del

\footnotetext{
${ }^{1}$ Tusell, Javier. Franco y los Católicos. La política interior española entre 1945 y 1957, Madrid, Alianza Editorial, 1984, pp. 197.

${ }^{2}$ Sobre este particular, resulta interesante la consulta del trabajo de José Ramón Montero: "El Boletín de la Asociación Católica Nacional de Propagandistas", pp. 83 y ss, en la obra colectiva: Las fuentes ideológicas de un régimen (España 1939-1945), Libros Pórtico, Zaragoza, 1978.

${ }^{3}$ Hermet, Guy. Los Católicos en la España Franquista, CIS, 1986, pp. 210 y ss.
} 
arzobispo de Toledo, monseñor Plá y Deniel; y sobre todo la del antiguo cerebro gris de la CEDA, Angel Herrera, que de esta manera inició un camino de acercamiento al régimen abandonando así la actitud de distanciamiento que hasta ahora éste había mantenido, y que le llevaría en 1947 a lograr la dignidad de obispo de Málaga.

Sin embargo, aunque el acceso del principal dirigente de la Acción Católica fuera respaldada por hombres de la entidad de Plá y Deniel, o Angel Herrera, esto no supuso en absoluto el apoyo unánime de la "familia" católica. Dejando a un lado la hostilidad con que José María Gil Robles recibió la noticia del nombramiento de Martín Artajo; lo más significativo fueron las reticencias de amplios sectores en el seno de la ACNP ante el ascenso político de uno de sus más preclaros dirigentes. Estas reticencias tuvieron una manifestación clara, en las dificultades que Martín Artajo tuvo que sortear a la hora de reclutar colaboradores para sus tareas en el Gobierno.

El relanzamiento de las actividades llevadas a cabo por la $\mathrm{ACNP}$, va a coincidir con un momento de declive de los poderes de la Falange en el aparato del Estado, dejando así varias parcelas de actuación a los propagandistas de Martín Artajo. Una de las áreas de la Administración que ahora van a pasar del control de la Falange a la del propagandismo católico será la relativa al control de la prensa, y por tanto, de la censura ejercida sobre la misma.

De la importancia que para el sector católico revestía el hacerse cargo de las competencias en materia de prensa, resulta de interés la carta dirigida por Martín Artajo al general Franco, en la que el ministro se manifiesta sobre esta cuestión, en los siguientes términos:

"Mi parecer sobre este punto es terminante: hay que ir a un nuevo Estatuto de Prensa, que conceda una mayor independencia a los periódicos, si bien con unos límites muy precisos y unas responsabilidades que, de verdad, les puedan ser exigidas.... Doy tanta importancia a este punto, en relación a la eficacia de las demás medidas políticas, que juzgo, mi general, imprescindible que el Gobierno se pronucie sobre él en esta inmediata reunión."

No obstante, el propio Matín Artajo reconocía que la elaboración del nuevo Estatuto podía ser lenta, de ahí la conveniencia por establecer un regimen provisional que:

"Pudiera consistir en restablecer en su pleno vigor la Ley de Prensa derogando una multitud de disposiciones de la antigua Vicesecretaría que la han aplicado con un criterio crecientemente restrictivo. Es, asimismo, urgente que se designe a un nuevo subsecretario de Educación Popular y un nuevo director de Prensa, los cuales apliquen criterios más amplios durante este período, que puede servir de prueba"

\footnotetext{
${ }^{4}$ Tusell, Javier. Ibid, pp. 93.

${ }^{5}$ Tusell, Javier. Ibid, pp, 93.
} 
No le resultó fácil a Alberto Martín Artajo conseguir que la responsabilidad directa y fundamental del régimen de prensa correspondiera a dos destacados propagandistas, pues hasta que finalmente aceptaron los hombres propuestos por Artajo, éstos habían rechazado por dos veces los puestos que se les ofrecían. Se trataba de Luis Ortiz como subsecretario de Educación Popular y de Tomás Cerro Corrochano como Director General de Prensa, ambos quedarían adscritos al Ministerio de Educación, regentado por José Ibañez Martín, otro importante propagandista.

El nombramiento de ambos produjo, como ya se ha indicado, el desplazamiento de la Falange de un área importante de la acción gubernamental y administrativa, hasta entoces dependiente de una vicesecretaría adscrita a la Secretaría General del Movimiento. Esta transferencia de competencias acarreó la salida de Gabriel Arias Salgado, y de Juan Aparicio, como subsecretario y director general, respectivamente. Los dos, volverían a ocupar puestos de responsabilidad en la remodelación del Gobierno acaecida en 1951.

Tanto Luis Ortiz Muñoz como Tomás Cerro Corrochano eran miembros de la Asociación de Propagandistas y procedían del mundo de El Debate. Apenas hubieron tomado posesión, a mediados de enero de 1946, se lanzaron a tratar de poner en práctica las ideas de Martín Artajo en lo que concernía a sus nuevos cometidos. A finales de ese mismo mes y comienzos de febrero, se dictaron varias disposiciones en torno a la modificación del régimen de prensa. La principal innovación consistió en establecer que la propuesta de nombramiento o destitución de un director de periódico correspondería a la persona natural o jurídica propietaria del mismo; sin embargo el acuerdo tomado debía de ser sometido a la aprobación del ministerio. Esta importante modificación, por la que venían suspirando desde hacia tiempo los hombres de la Editorial Católica y por tanto de la ACNP, no fue sancionado por Ibáñez Martín y la situación se mantuvo, en consecuencia, idéntica.

Si cosa tan natural como esta no pudo llevarse a la práctica, mucho menos lo fue el proyecto por sacar adelante una nueva ley de prensa que sustituyera a la de 1938. No faltó, sin embargo, el intento de Ortiz y Cerro, que elaboraron un borrador de proyecto de ley que Ibáñez Martín ni siquiera llegó a aceptar.

Pese al fracaso cosechado en sus propuestas, su labor no se detuvo; y así en marzo de 1946 se dictó una orden ministerial que autorizaba a la Dirección General de Prensa a atemperar el ejercicio de la censura, siempre que la "libertad" concedida a costa de esta nueva medida se ejerciera dentro de determinados límites ${ }^{6}$. A estas medidas, se unió el hecho de que en febrero de ese mismo año, se segregaron de la Dirección General de Prensa toda una serie de periódicos que ahora pasarían a manos de la Secretaría General del Movimiento, con lo que la censura de la Administración quedaba reducida a la nada.

Esto explica que las autoridades responsables del régimen de prensa, tuvieran tan poca capacidad de maniobra, y sobre todo de actuación, para con la prensa del 56.

${ }^{6}$ Femández Areal, Manuel. La Libertad de Prensa en España. 1938-1971, Edicusa, Madrid, 1971, pp. 
Movimiento que llegó en algunos momentos al vilipendio personal de Ortíz, y Cerro. Y lo más sorprendente de todo es que siendo ambos, como Martín Artajo, y como el propio ministro de Educación, hombres de la Editorial Católica, no obtuvieran para ésta ninguna situación de privilegio.

Buena prueba de ello, es que el diario Ya de ninguna manera puede ser considerado en estos años como un periódico seguidor de la línea de pensamiento propiciada por la Editorial Católica, su propietario al fin y al cabo, mientras estuviera al frente de su dirección Juan José Pradera. El "caso Pradera", como acertadamente lo llama Justino Sinova ${ }^{7}$, nos pone de manifiesto como un director de periódico nombrado en la época de Serrano Suñer al frente del Ministerio de la Gobernación, y con buenas amistades en la Secretaría General del Movimiento, podía llegar al enfrentamiento personal con el consejero delegado de la Editorial, Francisco de Luis, y no podía ser destituído por el Consejo de Administración de la empresa editora, ni aun cuando el control de la prensa hubiera pasado a manos de hombres de la propia Asociación.

Semejante situación nos indica, hasta que punto la presencia del Estado y la acción política predominaban sobre la realidad. Este hecho, según Tusell, contribuye muy significativamente a explicar el nacimiento de una nueva publicación, que fuera de los estrechos márgenes del diaro Ya, o de la revista Ecclesia, posibilitara al propagandismo católico un cauce distitinto para la difusión de sus inquietudes: la revista Criterio.

\section{LOS OBJETIVOS PERSEGUIDOS}

Cuando Fernando Martín-Sanchez Juliá, el creador y alma de Criterio, sea reelegido Presidente de la A.C.N de P. para un tercer mandato, el 7 de septiembre de 1947, pronunciará un discurso en el que al tratar de establecer la actitud del propagandista ante los acontencimientos del mundo, dirá:

"Venimos preocupándonos ya hace mucho tiempo de ello. Conversaciones con nuestros consiliarios, de nuestros consiliarios con otras altas autoridades, conferencias y consultas a quienes nos pueden aconsejar. Es un problema que a este Presidente le ha venido preocupando muchas horas y muchos pensamientos. Y como fruto todavía inmaduro o premio de esas consultas y conversaciones, y siguiendo pensando en voz alta con vosotros, os podría decir: (En este punto el Presidente expone algunos de sus proyectos) ${ }^{1+8}$

¿Estaría entre los proyectos de Martín-Sanchez Juliá, la comunicación a los asambleistas del anuncio de la publicación de la revista Criterio?. Pensamos que sí, pero el silencio guardado en este punto, a la hora de transcribir el discurso de

\footnotetext{
${ }^{7}$ Sinova, Justino. La Censura de Prensa durante el Franquismo, Espasa Calpe, Madrid, 1989, pp. 51.

${ }^{8}$ Martín-Sánchez Juliá, Femando. Ideas Claras, BAC, Madrid, 1959, pp. 501.
} 
Martín-Sánchez es bastante significativo de las disensiones previas a la aparición de la revista, dentro del seno de la de la Asociación.

Las discrepancias en torno a la oportunidad de su aparición, se ponen de manifiesto si tenemos en cuenta que se hicieron cuatro números de prueba en los que no se mencionaba para nada la situación española y tampoco a Franco. El propio Martín Artajo llegó a tildar a la revista de, "helada, híbrida, e incolora", pero lo que más parecía preocuparle era que, "la sorda hostilidad de una parte de los escritores...... escapa en reticencia y alusiones", y "temo que ahonde las diferencias entre la Editorial y el Gobierno". En semejantes términos se expresaba el Padre Ayala, fundador de la A.C.N. de P., al recomendar que no se trataran los problemas de España, pues en su opinión esto llevaría a la muerte de la revista ${ }^{9}$.

Superados estos inconvenientes, Criterio vió por fín la luz, con su aparición el 1 de noviembre de 1947. En el editorial de éste su primer número, bajo el expresivo título de Queremos, se puede leer el "leiv motif" de sus autores:

"Nace Criterio con el propósito de ser lo que significa su título: Medio para conocer la verdad. Queremos documentar íntegramente, informar a conciencia y orientar con opiniones fundadas, que por ahora versaran casi siempre sobre los hechos y las ideas de la vida exterior, estableciendo una crítica constructiva que permita configurar doctrinas y líneas institucionales......

Queremos así contribuir -y esperamos lograrlo- a la arquitectura de la nueva sociedad, que está surgiendo en las horas actuales entre una confusión de ideas que aturde y la agitación consiguiente de acciones que conmueven tristemente al mundo......"

\section{LA REVISTA (1947-1950)}

La presentación material de la revista es sobria, como corresponde a la mayoría de las publicaciones de la época. El nombre de la misma aparece en la parte superior de la primera página en letras grandes de color rojo, y lleva un subtítulo en letra más pequeña, también del mismo color, que reza: Revista de problemas contemporáneos. Bajo éste figura la fecha de aparición, y el número del ejemplar; así como el índice con sus respectivas secciones. La obra forma un total de tres volúmenes, de extensión desigual, encuadernados en tela editorial de color granate, en cuya portada aparece el título y subtítulo en letras doradas. Le acompaña a cada tomo un índice general de las materias y secciones abordadas en cada uno de ellos.

Tenía una periodicidad quincenal, y su número de páginas era de veinte, si bien en alguna ocasión se llegó a superar esta cifra, sobre todo a partir del año 1950. Se llegaron a publicar, de forma ininterrumpida, un total de 72 números, abarcando el período cronológico comprendido entre el 1 de noviembre de 1947, hasta el 15 de octubre de 1950 . No podemos decir que Criterio gustase de números extraordinarios,

\footnotetext{
${ }^{9}$ Tusell, Javier. Ibid. pp. 197.
} 
o monográficos; sin embargo no faltaron entre sus páginas el tratamiento de determinas cuestiones o acontecimientos que por su importancia requerían una consideración especial a la habitual. Su formato era de $25 \times 32 \mathrm{~cm}$, lo que la hacía semejante a un periódico normal.

Desconocemos si la publicación se vendía libremente al público, o era a través de suscripción, pero en cualquier caso su difusión debió de ser modesta. Su precio nunca sufrió alteraciones, 4 pesetas el ejemplar. El domicilio social era el mismo que el de la Editorial Católica, Alfonso XI, número 4, Madrid.

En cierta medida es una publicación anónima, pues no figura en ninguno de sus números a quien correspondía su dirección, ni su Consejo de Redacción. Pero cree Tusell, que se trató de una iniciativa de Fernando Martín-Sanchez Juliá, aunque tuviera como protagonistas principales a personas de una generación más joven: José María García Escudero, Joaquín Ruíz Gimenez, José Luis Gutiérrez, Bartolomé Mostaza y Nicolás Gonzalez Ruíz, figuraron, entre otros, en el Consejo de Redacción. Aunque una gran parte de los artículos que contenía Criterio se presentaban sin firma, no le faltaron una larga lista de colaboradores que sin duda alguna ayudaban a elevar el tono intelectual de la publicación; sin animo de ser exhaustivo, podemos citar, entre otros a : Gregorio Marañón, El Marqués de Lozoya, Federico Sopeña, Manuel Fraga Iribarne, José Luis Sampedro, K-Hito, Jorge Vigón, José María Valverde, Luis Felipe Vivanco, José María de LLanos, José Vasconcelos, Eugenio d'Ors, José María Pemán, Melchor Fernández Almagro, José Larraz, Angel González Palencia, Raimundo Paniker, Joaquín Rodrigo, Jesús Pabón......, por citar algunos de los más conocidos, aparte de los consejeros de redacción mencionados.

Como colofón a esta labor meramente descriptiva, resta por referirnos al tono general de la revista y a las secciones en que aparece dividida. Hemos de señalar a este respecto, que nos hallamos ante una publicación extraordinariamente prolija y densa en noticias, comentarios, reseñas, opiniones, informes, crónicas, etc., lo que unido a la letra pequeña con que eran redactadas muchas de sus secciones, la convierten en una revista de incómoda lectura. Situación ésta que se compensaba gracias a la cantidad de dibujos, gráficos, huecograbados, e incluso viñetas humorísticas procedentes muchas de ellas de la prensa extranjera, también incluía numerosos anuncios publicitarios. Por otro lado, no podemos decir que la revista presentase un carácter rígido en cuanto a la distribución de sus secciones, pues los contenidos de muchas de ellas eran fácilmente intercambiables. Naturalmente, con el tiempo se fueron ampliando algunas, se crearon nuevas, se fusionaron entre sí, o simplente desaparecieron.

Cada número se abría con un Editorial principal, al que acompañaban dos o tres más de carácter más secundario, que nunca faltaron. Los comentarios abordados por los mismos, hacían referencia a algún tema de actualidad casi siempre acaecido en el extranjero; si bien, en diversas ocasiones se trataron asuntos relacionados con nuestro país. Rara vez el editorial polemiza, pero cuando lo hace se menciona sin reparos al sujeto con quien se entabla la polémica, sobre todo si se trata de la Falange.

Además de los editoriales, la revista contaba con una importante sección titulada Hechos y Juicios, que como su propio nombre indica, estaba destinado a dar a 
conocer y valorar, en forma resumida las más diversas noticias o comentarios de la actualidad internacional, o en ocasiones nacional.

Es de destacar la sección dedicada a las Colaboraciones, en ellas los más diversos temas se daban cita de acuerdo con la especialidad de cada colaborador. Las cuestiones que con más frecuencia asomaron a las páginas de Criterio eran las relacionadas con el arte, la religión, la literatura, las ciencias experimentales....etc.

Otra sección importante era la dedicada a reproducir las Crónicas recibidas desde el extranjero. De los países anglosajones, y sobre todo desde Hispanoamérica era de donde más se recibían. No creemos que Criterio tuviera desplazados corresponsales exclusivos por todo el mundo, sino que más bien debía de tratarse de personas afínes a la orientacion de la revista que ejercían este papel enviando noticías y comentarios sobre diversos hechos acontecidos en sus respectivas naciones.

Especial relevancia tenía la sección titulada Textos y Documentos; en ella se reproducían de forma íntegra o muy ampliada, diversos textos legales, políticos, pastorales, encíclicas, o conferencias pronuciadas por hombres ilustres tanto de España, como del extranjero.

Finalmente, la revista contenía también otras seciones más o menos importantes como la dedicada a glosar la figura de un personaje público relevante en ese momento; la dedicada a las cartas al director; la recensión de libros; las paginas dedicadas a asuntos económicos o cuestiones sociales; la destinada a dar a conocer la doctrina de los Papas; o las dedicadas a temas tan variados como el arte, la ciencia, el deporte, el espectáculo,la técnica....etc. La última página siempre estuvo dedicada a dar cuenta de todo un rosario de anécdotas curiosas que en el mundo social, político, literario, etc. le habían ocurrido a grandes personajes de la historia o de la actualidad.

\section{LOS GRANDES TEMAS DE LA REVISTA A TRAVES DE SUS EDITORIALES}

En razón del objetivo básico de la revista, la mayoría de los editoriales se refieren a hechos o acontecimientos ocurridos fuera de nuestras fronteras; sin que por ello se deje de abordar en los mismos, a cuestiones relacionadas directa, o indirectamente con la vida nacional. No faltaron, sin embargo, aquellos que de forma explícita aludían a la situación interna de España.

Dadas las características de este trabajo, no nos proponemos analizar la evolución de los editoriales, sino simplemente esbozar aquellos hechos que para los hombres de Criterio revistieron mayor importancia, a juzgar por la transcendencia que parecieron darle a los mismos; y que podríamos resumir alrededor de los siguentes puntos:

\section{Comunismo y anticomunismo}

Como no podía ser menos, dado el ambiente que se respiraba en la época, el 
comunismo es el gran enemigo a batir. Manuel Ramírez ha escrito que el anticomunismo practicado durante toda la vida del franquismo y singularmente en los años del aislacionismo internacional, "será la cobertura que se agitará una y otra vez y a la que cabrá atribuirle las vicisitudes y desgracias que la política nos depare"10.

El punto de partida para la crítica anticomunista desplegada desde Criterio, parte de dos hechos bien significativos. El primero, la presencia de la URSS en pleno corazón de Europa, lo que en su opinión, se traducía en una constante amenaza para la paz. El segundo, al que se otorga una mayor importancia, se refería a la presencia de los partidos comunistas en el seno de las nacientes democracias continentales, lo cual conllevaba permitir al "enemigo" convivir en la propia casa.

Ante una amenaza como esta, ¿Qué deben hacer las democracias si quieren preservar su precaria subsistencia?, se pregunta Criterio. La respuesta no podía ser más contundente, "la solución política provisional de las democracias ante el comunismo no puede ser más que una: la declaración del comunismo fuera de la ley, poniéndole así trabas decisivas a su actuación política"11. No es de extrañar pues, que desde las páginas de Criterio se salude con alegría la promulgacion de leyes que, sobre todo en las Repúblicas Hispanoamericanas, prohibían la actuación de los partidos comunistas o permitían las depuraciones de "presuntos" comunistas en sus administraciones. Hecho éste, que es interpretado por Criterio como, "una indirecta reivindicación de la conducta de España", como precursora en la lucha contra el comunismo $^{12}$.

Ahora bien, si el poner al comunismo fuera de la ley es sólo una medida provisional a adoptar, la resolución del problema sólo podía pasar por establecer "soluciones totales" a la cuestion. Es ahí, donde Criterio postula la idea de un anticomunismo "positivo", que supere un marxismo y un antimarxismo en los que hay tanto de común que, "las afirmaciones dialécticas más parecen confundirse que oponerse"13.

¿En qué se va a fundamentar ese anticomunismo de carácter "positivo" propugnado por Criterio?. En un intento por tratar de llamar la atención sobre el camino erróneo que, a su parecer, están siguiendo algunas democracias europeas, especialmente Italia y Francia, en el momento de elaborar sus nuevas Constituciones, desde las páginas de la revista parece quererse teorizar sobre la incapacidad de estos textos constitucionales para hacer frente a las actividades desplegadas por los diversos partidos comunistas.

Esta situación, obliga a Criterio a proyectar su anticomunismo hacia una triple dirección, que revistiendo caracteres de signo religioso, político y social, puedan evitar la subversión comunista, siempre que impere, "una recia voluntad de ponerlas en práctica"14.

\footnotetext{
${ }^{10}$ Ramírez, Manuel. España 1939-1975, Guadarrama, Madrid, 1978, pp. 86.

${ }^{11}$ Crit. $\mathrm{n}^{\circ} 10$, de 15 marzo de 1948. pp. 1.

${ }^{12}$ Crit. $\mathrm{n}^{\circ} 4$, de 15 de diciembre de 1947. pp. 1.

${ }^{13}$ Crit. $\mathrm{n}^{\mathrm{0}} 11,1$ de abril de 1948. pp. 6.

${ }^{14}$ Crit. $\mathrm{n}^{\mathrm{O}}$ Ibid.
} 
Respecto al espíritu religioso, se proclama nada menos, que convertir en postulados de eficacia política las "obras de misericordia" y "las bienaventuranzas", dado que así se fomentaría un espiritualismo cristiano que "se opondría a la idolatría de un progreso material y social concebido únicamente como un reparto de la producción cada vez mayor de bienes y recursos"15.

Más importancia revisten los aspectos sociales, pues es desde éstos y no desde los presupuestos políticos, donde debe encontrarse la solución anticomunista de carácter "positivo". ¿Cuál es la reforma social propiciada por Criterio?. Desde luego esta no pasa por una política de estatificaciones para así, "distraer las apetencias obreras". Se abogaría así, por una cooperación entre las clases sociales que estaría inspirada, parafraseando a Marx, en la máxima: "Productores de una misma empresa asociaos". De esta manera, Criterio concibe a la empresa como la unidad económica de carácter "corporativo" capaz de unificar los intereses contrapuestos de trabajadores y empresarios.

Solución semejante es la propiciada para la agricultura, de ahí que se insista en que es necesario fomentar el sistema de arriendos o aparcerías en las pequeñas propiedades, y un tratamiento industrial de las grandes explotaciones, todo ello con el fín de unir al obrero a, "la suerte de la propiedad empresaria."

Pero si como hemos indicado la reforma social no debe tener como base la estatificación de la economía, ¿Qué papel le ha de corresponder al Estado en las relaciones económicas? Parece abogarse desde las páginas de la revista por un cierto liberalismo al considerarse que las funciones del Estado en este campo deben tener un carácter residual, que en nigún caso supongan el ejercicio de actividades que deben estar en manos de particulares; así, "el anticomunismo debe significar por lo tanto el prevalecimiento en el mundo económico, de la iniciativa privada, motor extraordinario de creación y de riqueza"17.

Por último, desde la perspectiva política, Criterio se pronucia por la creación de un Estado "moderno", orgánico y representativo, que bien puede revestir la forma monárquica o republicana de tipo presidencialista, pues "el sufragio universal inorgánico y democrático ha sido superado desde que hizo su aparición el comunismo en el estadio de la política". La teoría de la democrácia orgánica aparece de esta forma, como la única alternativa válida frente a la democracia liberal. Ahora bien, parece que los redactores de Criterio no creen demasiado próximo el establecimiento de su particular modelo de Estado; por ello preconizan para las democracias occidentales un uso, "racionado del sufragio universal inorgánico bien en lo que se refiere al alcance de sus atribuciones, bien en cuanto a los periódos de renovación de los organos del Estado que por éste mecanismo se elijan"18.

Se muetran firmemente partidarios de que el Estado abrace la forma confesional, pues se considera que "hay un pecado de escándalo del Estado, y las llamadas

\footnotetext{
15 Crit. $\mathrm{n}^{\mathrm{o}}$ Ibid.

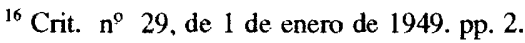

${ }^{17}$ Crit. $\mathrm{n}^{\mathrm{o}}$ Ibid.

${ }^{18}$ Crit. $n^{\text {E Ibid }}$
} 
libertades de cultos no son más que eso"19.

Por otro lado, se proclaman fervorosos defensores de los derechos de la persona humana, pero no sin antes haber establecido algunas disticiones sobre lo que consideran como tales derechos. De esta forma, reconocen como derechos esenciales de la persona humana: el derecho a la vida, al alimento, al culto a dios, a la elección de estado, de profesión de hogar, etc.; derechos que, en opinión de Criterio, el comunismo siempre atropella. Pero junto a estos, estan otros, los puramente políticos, que tienen un carácter muy secundario respecto a los primeros ${ }^{20}$.

Ahora bien, si todo cuanto hemos dicho tiene su razón de ser en aquellos países donde la amenaza comunista está latente, no deja de preguntarse Criterio: ¿Qué ocurre con las naciones en que ésta amenaza parece conjurada?, ¿Qué sentido tiene la aplicación de la doctrina social de la Iglesia allá donde las posibilidades de éxito del comunismo parecen suspendidas?. Estamos, aunque sin mencionarlo explícitamente, ante una clara referencia al caso de España, de ahí que se afirme que, "los mejores momentos para realizar nuestras obras sociales son aquellos en los que reina la paz y parece suspendida o lejana la amenaza comunista"21.

\section{La posición de España ante el mundo}

Dado el carácter de la revista, la mayoría de las informaciones estaban dedicadas a hechos ocurridos en el exterior, que en la mayoría de los casos nada tenían que ver con España. Sin embargo no faltaron editoriales tendentes a poner de manifiesto diversos aspectos de la política internacional en la que nuestro país se hallaba directa o indirectamente implicado. Lo que se dió en llamar "caso de España" ante la ONU; la participación española en el proyecto de unidad europea; $y$, el posible ingreso de España en la reciente creada OTAN, son los aspectos más relevantes que los editoriales de Criterio abordaron con suma frecuencia.

\section{A) El Caso de España}

Desde los inicios de la revista, y hasta el final de la vida de la misma; el llamado "caso de España" en la ONU es seguido de forma minuciosa. La mayoría de los editoriales dedicados a éste tema son una constante reprobación de lo se se considera injusto proceder de la ONU contra España al intervenir aquella organización internacional sobre los asuntos internos de ésta. Naturalmente los manejos contra nuestro país no tienen otro orígen que la "conspiración comunista". De ahí, que Criterio denucie la "falta de visión" en las potencias occidentales al no ver la mano del comunismo en todo esta situación ${ }^{22}$. Desde las páginas de Criterio se postula así, que el respeto a la soberanía e independencia de España le lleva a no admitir un

\footnotetext{
${ }^{19}$ Crit. $n^{\circ}$ Ibid.

${ }^{20}$ Crit. $\mathrm{n}^{\circ}$ Ibid.

${ }^{21}$ Crit. $\mathrm{n}^{\mathrm{o}} 22$, de 15 de septiembre de 1948. pp. 2.

${ }^{22}$ Crit. no 1 , de 15 de noviembre de 1947. pp. 2.
} 
veredicto de la ONU "ya que en el tribunal que la ha juzgado han tomado asiento los enemigos más calificados de España -Rusia y sus satélites- sin escuchar a quien se condena" ${ }^{123}$.

Sin embargo lo que más parece indignar a los hombres de Criterio es el trato indiscriminado que se le concede a España con respecto a otros países. Así, cuando se reconozca por parte de Inglaterra a la China comunista por la simple aceptación del hecho de que el gobierno comunista es el que ejerce la autoridad en China, la respuesta de Criterio no puede ser más clara, "mientras esto ocurre España no acaba de ver normalizada sus relaciones con varios países y se le excluye de la ayudas económicas porque para nuestro régimen no se aplica ni siquiera el criterio oportunista de que realmente ejerce la autoridad en nuestro territorio" 24 .

Finalmente, cuando se anunció que en la próxima Asamblea de la ONU, los EEUU votarán por la derogación del acuerdo de 1946, que estableció la retirada de embajadores de Madrid, la noticia es recogida desde las páginas de Criterio con la mayor frialdad y escepticismo. El comentario de no puede ser más expresivo: "buenas palabras para disfrazar malas intenciones". Ni siquiera, cuando algunos paises europeos y los EEUU anuncien el hecho de enviar un embajador a Madrid. Criterio no mostrará ni un ápice de satisfacción ante la noticia, pues esto sólo será considerado como "el remedio a una falta de cortesía cometido contra España"25.

\section{B) La Unidad Europea}

Son muy frecuentes en Criterio las páginas dedicadas a glosar el proceso de unificación europea. Su idea de Europa no es la de considerar a ésta como una mera agregación de recursos económicos, sino como, "un acervo de valores espirituales, basados en una cultura, una religión, un pensamiento político, adquirido todo ello a fuerza de centurias de historia común $\mathrm{y}$, de un concepto distinto de la vida, del Estado, del gobierno, y de la persona humana"; todo ello para tratar de indicarnos que, "cualquiera que sea el criterio que se adopte para definir a Europa salta a los ojos que la URSS no tendría lugar en el conjunto"26.

Criterio, simpatiza con la idea federalista por ser la única capaz de crear un mentalidad europea común, pero se critica a los movimientos federalistas, pues estos adolecen de un "estrecho academicismo democrático" ${ }^{27}$. En todos los artículos dedicados a la semblanza de la unidad europea se recuerda la injusticia que con España se comete. No se admite así, la exclusión de España del Movimiento Europeo, de ahí que se anuncie que, "cuando llegue el día en que la Unión Continental tenga que resolverse sin dilaciones, el Comité español será el que represente al Estado español y no el formado por algunos extranjeros de acuerdo con

\footnotetext{
${ }^{23}$ Crit. $\mathrm{n}^{\circ} 38$, de 15 de mayo de 1949. pp. 1.

${ }^{24}$ Crit, $n^{\mathrm{e}} 54$, de 15 de enero de 1950, pp. 2.

${ }^{25}$ Crit. $n^{\circ} 55$, de 1 de febrero, 1950 . pp. 1.

${ }^{26}$ Crit. $n^{\circ} 5$, de 1 de enero de 1948. pp. 1.

${ }^{27}$ Crit. no 29, de 1 de enero de 1949. pp. 1.
} 
algunos españoles determinados" 28 , en una clara referencia a la participación en el Movimiento de determinados exiliados españoles como Salvador de Madariaga.

En definitiva se concluye afirmando que la unión económica, política, social, es importante pero, "la cristiandad no está unida y en ésta división reside el problema más grave" 29 .

Todo el esfuerzo de Criterio tiende a dar a conocer las aportaciones que España está haciendo en su interior por acercar nuestro país a la unidad europea, y pone como ejemplos, las conferencias y estudios desarrollados por el ex-ministro de Hacienda José Larraz, o la creación de instituciones como la Sociedad de Estudios Económicos Españoles y Europeos. Todo ello con el fín de establecer líneas de actuación desde fuera del Gobierno al objeto de que éste en su momento, "no se vea en la situación de improvisar"30.

\section{C) España y Los Bloques}

Se parte de la idea de que España no sólo forma parte de occidente sino que es, junto con Portugal, "la esencia de occidente". Sin embargo, denucia Criterio, que no parece que desde fuera esto se vea así, pues hay una designación "a dedo" de los países que forman occidente ${ }^{31}$.

Desde esta perspectiva se analiza la posible pertenencia de España al bloque militar occidental por excelencia, la OTAN. En éste sentido se indica que si el bloque tiene como objetivo preparar la guerra, España, "tendría bien ganada su tercera neutralidad pues llegado el fatal desenlace España pondría sus condiciones que deberían ser satifechas desde ahora". Pero si el bloque es para asegurar la paz, "imaginar una occidente sin España es edificar en el vacío"32.

Todas estas ideas son las expresadas por Martín Artajo al responder a un editorialista del Evening Star londinense, según el cual España en caso de guerra. cosa que entonces se consideraba como probable, se alinearía junto a las potencias occidentales. La respuesta del ministro no deja lugar a dudas, "España siempre estará frente al comunismo y allá donde peligre lo que antes que nadie y con notable adelanto, acudimos a salvar los españoles. Pero no se enrolará en bloques que invocan desinteresados objetivos, difícilmente discutibles"33. Criterio recela de la participación de España en una alianza militar junto a países que se piensa han incurrido en una cadena de concesiones inauditas frente al comunismo y que por tanto no puede España, "hipotecar sus conquistas con quienes se han revelado incapaces de afrontar sus propias responsabilidades" ${ }^{\text {"34. }}$.

\footnotetext{
${ }^{28}$ Crit. $\mathrm{n}^{\mathrm{o}} 34$, de 15 de marzo de 1949. pp. 1

${ }^{29}$ Crit. $\mathrm{n}^{\mathrm{o}} 29$, de 1 de enero de 1949. pp. 1.

${ }^{30}$ Crit. $n^{\mathrm{9}} 61$, de 15 de mayo de 1950. pp. 1.

${ }^{31}$ Crit. $n^{9} 7$, de 1 de febrero de 1948. pp. 1.

${ }^{32}$ Crit. $n^{\mathrm{Q}}$ Ibid.

${ }^{33}$ Crit. $\mathrm{n}^{\mathrm{0}} 21$, de 1 de septiembre de 1948. pp. 1 .

${ }^{34}$ Crit. $n^{\circ}$ Ibid.
} 
En definitiva, ante la imposibilidad manifiesta de ingreso de nuestro país en la Alianza Atlántica, Criterio buscará una especie de consolación en cantar las excelencias que para España le ha reportado la firma de otro pacto: el Pacto Iberico con Portugal. No es de extrañar que cuando éste país ingrese en la O'TAN, los redactores de la revista sobrevaloren la importancia de éste acuerdo con el país vecino y lo presenten como una forma indirecta de sentirse vinculado a la defensa de occidente ${ }^{35}$.

\section{El camino de la institucionalización}

El rumbo que ha de seguir la institucionalización del régimen, tiene su orígen en una peculiar tesis a la que calificamos de "totalitarismo como defensa": "El movimiento Nacional fue el último y desperado esfuerzo a que recurrió para salvar su existencia, no ya ideológica, sino hasta geográfica, la nación española, después de que se habían agotado todos los recursos pacíficos y recorrido todas las vías legales" ${ }^{36}$. Fueron pues, en opinión de Criterio, las izquierdas las que con su sistemática resistencia a aceptar en el juego democrático a las derechas colaboracionistas, propiciaron el estallido del conflicto. Un conflicto que por cierto, y abundando en la tesis del "totalitarismo como defensa", no debe contemplarse como un mero pronuciamiento o rebeldía de un interés partidista o de clase, puesto que fue: "la legítima defensa de los ideales e intereses nacionales básicos ${ }^{137}$. De ahí, que ésta no sea considerada por Criterio como un drama, sino todo lo contrario, como: "el supremo recurso para lograr una convivencia ordenada de los españoles.... Pues el Estado que surgió de ella llevaba en su bandera una profunda revolución que unió a los españoles en un plano diferente del político" ${ }^{138}$.

Ahora bien, una vez superados los avatares de la contienda lo importante para Criterio es garantizar la permanencia del Estado nacido como consecuencia de aquella. Una garantía que solo puede venir de las instituciones, pues la estabilidad del régimen, en clara referencia a Franco, "no podrá apoyarse indefinidamente en una persona humana, aun cuando sea como en este caso, providencial" ${ }^{23}$.

Franco se configura así, como no podía ser menos, en la clave de bóveda de todo el proceso de institucionalización, ya que sólo a él le corresponde, al parecer de Criterio, dirigir y conducir la evolución política de España al compás de las circunstancias. No es de extrañar pues, que Franco sea considerado el "punto insustituible de confluencia de fuerzas políticas" ${ }^{\prime 40}$.

Siempre sin perder de vista lo anterior, ¿Cuál era el tipo de estructura política preconizada por Criterio para España?. Desde luego si una cosa se tenía clara, era

\footnotetext{
${ }^{35}$ Crit. $n^{\circ} 48$, de 15 de octubre de 1949. pp. 1 .

${ }^{36}$ Crit. $\mathrm{n}^{\mathrm{9}} 18$, de 15 de julio de 1948. pp. 1 .

${ }^{37}$ Crit. Ibid.

${ }^{38}$ Crit. $\mathrm{n}^{\mathrm{Q}} 38$,de 1 de abril de 1949. pp. 2.

${ }^{39}$ Crit. Ibid.

${ }^{40}$ Crit. Ibid.
} 
que los procesos constituyentes europeos del momento, Italia y Francia sobre todo, tenían mucho de "ejemplo a la inversa". La democracia orgánica será pues, el camino a seguir en la institucionalización, puesto que era considerada la única capaz de organizar un fuerte Estado representativo capaz de "conjugar la indispensable fortaleza de la autoridad con las legítimas libertades e intervenciones públicas de los gobernados"

Como ya sabemos, en 1947 se promulgó la Ley de Sucesión a la Jefatura del Estado en virtud de la cual Franco obtenía la posibilidad de nombrar su heredero a título de rey. Si España quedaba constituida en reino, ¿Cuál era el tipo de monarquía por el que abogaba Criterio?. En primer lugar la revista se ocupa en deshacer ia vinculación entre monarquía y régimen liberal, pues la monarquía que ha de venir debe perpetuar, "los principios triunfantes del 18 de julio"42. En segundo lugar, la monarquía es considerada como la fórmula más segura para dar continuidad a la Jefatura del Estado, e impedir así toda apetencia para ocuparla. Tal es el sentido que Criterio otorga a la entrevista mantenida por D. Juan con Franco el 25 de agosto de 1948, pues de ella se dice que, "tiende a asegurar la continuidad de una situación estable en la más alta cumbre del poder político" ${ }^{\text {"43 }}$. En definitiva se trata por parte de Criterio, de unir la suerte de la monarquía a la del régimen franquista.

Aceptados por Criterio los términos en que se expresaba la Ley de Sucesión; las elecciones, sobre todo las de carácter municipal son el otro sendero por el que habría de discurrir la paulatina institucionalizacion del régimen. Se recuerda el deber de votar, deber que lleva aparejado consigo el de "elegir cuidadosamente aquellos candidatos que el elector considere más dignos de ostentar la representación que se les confiere" ${ }^{\prime 44}$. Se insiste en la importancia que unas elecciones municipales tienen dado que, "en el ámbito local debe resolverse el problema de la mejora del pueblo y de la reforma social" ${ }^{\prime 4}$. Por otro lado, le atribuyen a éstas un carácter meramente administrativo, tratando así de restarles un cierto matíz político y profundizando, por el contrario, en los aspectos de la gestión; llegando a abogar por la participación en los comicios electorales locales incluso, "a los que fueron concejales durante la República, siempre que no recaiga en ellos, naturalmente, tacha legal de ninguna clase ${ }^{46}$.

En mucha menor medida, también hay alusiones a las Cortes Españolas, como organo que por antonomasia encarnaba la representación del pueblo español de aquellos momentos. De ellas, se destacaba el desequilibrio entre la representación de las "profesiones liberales", y las que corresponden a los organismos locales de carácter territorial o sindical ${ }^{47}$.

\footnotetext{
${ }^{41}$ Crit. $n^{\circ} 18$, de 15 de julio de 1948. pp. 1.

${ }^{42}$ Crit. no 34, de 15 de marzo de 1949. pp. 2.

${ }^{43}$ Crit. $n^{\circ} 23$, de 1 de octubre de 1948. pp. 1.

${ }^{44}$ Crit. $\mathrm{n}^{\mathrm{0}} 26$, de 15 de noviembre de 1948. pp. 1 .

${ }^{45}$ Crit. $n^{\mathrm{O}}$ Ibid.

${ }^{46}$ Crit. $n^{\circ}$ Ibid.

${ }^{47}$ Crit. $\mathrm{n}^{\mathrm{O}}$ Ibid.
} 
En definitiva nada más idóneo que estas palabras para mostrarnos cual era el camino de la institucionalización propugnada por Criterio: "Evolución de lo personal a lo institucional, de lo discrecional a lo jurídico, de lo autoritario a lo representativo" ${ }^{\text {"48. }}$.

\section{EL FINAL}

Nada hay en el último número de Criterio que nos haga sospechar que estamos ante su final, ni siquera un editorial a modo despedida de sus lectores. Tan sólo unas breves líneas en la última página que rezan: Criterio se despide de sus lectores y les agradece la benévola atención que le han prestado.

Tusell, atribuye su corta vida a la propia división interna entre los sectores del catolicismo político del momento; a un tono intemporal que no era el más adecuado para una difusión muy extensa, de ahí que fuera apagándose lentamente hasta desaparecer el 15 de octubre de 1950. Estando, por tanto, cerca de enlazar con el diario Ya recuperado en 1952 por la Editorial Católica con la autonomía para nombrar un director.

${ }^{48}$ Crit. № 35 de 1 de abril de 1949. 